\title{
Spinal Cord Injuries without Visible Bone Lesions: Analysis of Four Consecutive Cases
}

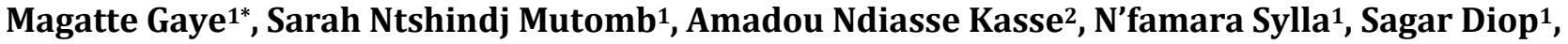 \\ Alvin Nah Doe', Aboubacar Sidiki Sangharé2, Mouhamadou Habib Sy², Youssoupha Sakho' \\ ${ }^{1}$ Department of Neurosurgery, Grand-Yoff General Hospital, Dakar, Senegal \\ ${ }^{2}$ Department of Orthopedics and Trauma Surgery, Grand-Yoff General Hospital, Dakar, Senegal \\ Email: *magou762003@yahoo.fr
}

How to cite this paper: Gaye, M., Mutomb, S.N., Kasse, A.N., Sylla, N., Diop, S., Doe, A.N., Sangharé, A.S., Sy, M.H. and Sakho, Y. (2018) Spinal Cord Injuries without Visible Bone Lesions: Analysis of Four Consecutive Cases. Open Journal of Orthopedics, 8, 95-101.

https://doi.org/10.4236/ojo.2018.83012

Received: January 25, 2018

Accepted: March 6, 2018

Published: March 9, 2018

Copyright $\odot 2018$ by authors and Scientific Research Publishing Inc. This work is licensed under the Creative Commons Attribution International License (CC BY 4.0).

http://creativecommons.org/licenses/by/4.0/

\begin{abstract}
Objectives: Interest of this study is to report four cases of spinal cord injuries without bone lesion. Evolution of the injured patients according to the initial clinic assessment at admission and the treatment performed are discussed. Materials and Methods: From January to December 2016, we performed a retrospective study at the Neurosurgery Department of Hospital General Grand Yoff of Dakar. Four patients were followed for spinal cord injury without visible bone lesions. We analyzed the clinical, radiological, therapeutic and evolutionary data. Trauma caused by stabbing was excluded. Results: In a year, 83 cases of spinal trauma with neurological deficit were hospitalized in the department. Among them, 4 had spinal cord injuries without visible bone lesions. The average age was 31.7 years with extremes ranging from 14 to 47 years. The sex ratio of male/female was 3 . We have recorded 2 cases of road traffic accidents, 1 case of fall from height and 1 case of sports accident. On the neurological level, we found 3 cases of tetraplegia, and 1 brachial monoplegia. Computed tomography in all patients was normal. All of them benefited from magnetic resonance imaging that showed spinal cord injury. All patients were under conservative treatment. One patient fully recovered, two partially and one passed away. Conclusion: In presence of any post traumatic myelopathy case, the absence of disco-vertebral lesions should bring to mind the SCIWORA as well as indicate the realization of magnetic resonance imaging.
\end{abstract}

\section{Keywords}

Spinal Cord Injuries, Trauma, MRI

\section{Introduction}

Spinal cord injury without radiological abnormalities, formerly called SCIWORA 
is a rare entity. It is often found in children and mostly affected the cervical spine. The context of spinal cord syndrome without bone lesions was introduced by Lloyd in 1907 [1]. In 1982, the acronym SCIWORA was introduced by Pang and Wilberger, and with the advent of MRI, diagnosis is easier. We made the report on four consecutive cases of SCIWORA in one year. In our knowledge, it is the first study in sub-Saharan countries.

\section{Patients and Method}

From January to December 2016 at the department of neurosurgery of Hopital General Grand Yoff, we collected retrospectively all cases of traumatic spine with neurological deficit. We selected all patients entering in the criteria of SCIWORA meaning no bone lesion or displacement on CT scan studies; but MRI findings were abnormal. We studied socio-demographic, clinical characteristics and we analyzed neuroimaging findings. A conservative treatment has been done and 12 to 18 months follow up have been conducted.

\section{Results}

During 2016, eighty three (83) cases of spine trauma with neurological deficit were hospitalized in our department. Among them, they were four spinal cord injuries without visible bone lesions on X-ray and CT scan. The average age was 31.7 years with extremes ranging from 14 to 47 years. The sex ratio male/female was 3 (Table 1).

We recorded two cases of road traffic accidents, one case of fall and one of sport's accident (Table 1).

Three patients had sensory disturbance with sphincter disorders. Respiratory disorders were found in one of them (Case $\left.\mathrm{N}^{\circ} 4\right)$.

$\mathrm{X}$-ray and CT scans of the cervical spine in all patients were normal. MRI showed spinal cord injury for three patients (Cases $\mathrm{N}^{\circ} 1,2,4$ ) and a syringomyelia in one case (Case $\mathrm{N}^{\circ} 3$ ) (Table 1 ).

A conservative treatment was administrated to all patients: corticosteroids, immobilization with a cervical collar and physiotherapy.

Out of four patients, only one recovered fully few month later (case $\mathrm{N}^{\circ} 3$ ). The two others injured by fall (Case $\mathrm{N}^{\circ} 1$ ) and after sport accident (Case $\mathrm{N}^{\circ} 2$ ) have recovered partially from their spinal cord contusions. They went FRANKEL $B$ to FRANKEL C. The fourth patient (Case $\mathrm{N}^{\circ} 4$ ) was transferred to the intensive care unit (ICU) and he passed away three days after from spinal shock.

\section{Discussion}

Spinal cord injury without radiographic abnormality (SCIWORA) is a spinal cord injury (SCI) without fractures or bony mal alignment on either plain radiographs or CT scan. SCIWORA is most commonly seen in the pediatric age group with an incidence varying from $19 \%$ to $34 \%$ of the spinal cord injuries of the child [2]. The anatomical and biomechanical features of the spine in children, 
Table 1. Demographic data, clinical characteristics magnetic resonance findings, outcome and follow up of all cases.

\begin{tabular}{|c|c|c|c|c|c|c|}
\hline Patients & Age/Sex & Pathomechanism & Presentation & $\begin{array}{c}\text { Neuro imaging: } \\
\text { MRI }\end{array}$ & Treatment & $\begin{array}{c}\text { Outcome/ follow } \\
\text { up }\end{array}$ \\
\hline $\mathrm{N}^{\circ} 1$ & $\begin{array}{c}14 \\
\text { years/male }\end{array}$ & $\begin{array}{l}\text { fall from a tree } 3.5 \mathrm{~m} \\
\text { height } \\
\text { reception on the } \\
\text { frontal head }\end{array}$ & $\begin{array}{c}\text { Incomplete } \\
\text { Tetraplegia/(2/5 } \\
\text { of cotation) } \\
\text { Sensible } \\
\text { level at } \mathrm{T} 2 \\
\text { Abolition of deep } \\
\text { tendon reflex }\end{array}$ & $\begin{array}{l}\text { spinal cord } \\
\text { contusion } \\
\text { extended from } \\
\text { C3 to C6 } \\
\text { (Figure 1) }\end{array}$ & conservative & $\begin{array}{l}1 \text { year and a } \\
\text { month later } \\
\text { Able to move } \\
\text { hands and feet } \\
\text { Eating himself }\end{array}$ \\
\hline $\mathrm{N}^{\circ} 2$ & $\begin{array}{c}23 \\
\text { years/female }\end{array}$ & $\begin{array}{l}\text { forward roll during sport } \\
\text { hyperflexion-compression }\end{array}$ & $\begin{array}{l}\text { neck pain } \\
\text { a complete } \\
\text { tetraplegia } \\
\text { No sensitive } \\
\text { disorders }\end{array}$ & $\begin{array}{l}\text { spinal cord } \\
\text { contusion } \\
\text { extending from } \\
\text { C2 to C6 } \\
\text { (Figure 2) }\end{array}$ & conservative & $\begin{array}{c}1 \text { year and } 6 \\
\text { months later } \\
\text { Able to move his } \\
\text { members } \\
\text { Gluteal pressure } \\
\text { ulcers } \\
\text { Assistance } \\
\text { for meal }\end{array}$ \\
\hline $\mathrm{N}^{\circ} 3$ & $\begin{array}{c}47 \\
\text { years/male }\end{array}$ & $\begin{array}{c}\text { car driver, hit from } \\
\text { behind by a truck } \\
\text { Whiplash. }\end{array}$ & $\begin{array}{l}\text { right brachial } \\
\text { monoplegia }\end{array}$ & $\begin{array}{l}\text { syringomyelia } \\
\text { (Figure 3) }\end{array}$ & conservative & $\begin{array}{l}\text { Full recovery } 5 \\
\text { month later }\end{array}$ \\
\hline $\mathrm{N}^{\circ} 4$ & $\begin{array}{c}43 \\
\text { years/male }\end{array}$ & $\begin{array}{c}\text { victim of a car crash } \\
\text { Whiplash. }\end{array}$ & $\begin{array}{c}\text { complete } \\
\text { tetraplegia } \\
\text { difficulties to } \\
\text { breathe } \\
\text { sensory level } \\
\text { at C7 }\end{array}$ & $\begin{array}{l}\text { spinal cord } \\
\text { contusion } \\
\text { extending from } \\
\text { C5 to C6 } \\
\text { (Figure } 4 \text { ) }\end{array}$ & conservative & $\begin{array}{l}\text { He passed away } \\
\text { three days after }\end{array}$ \\
\hline
\end{tabular}

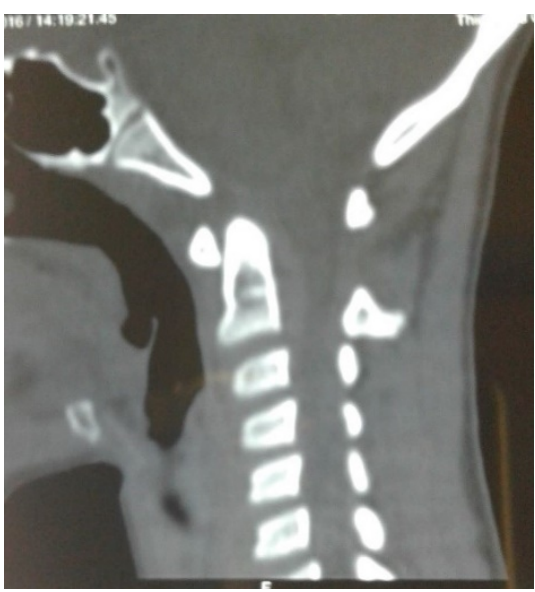

(a)

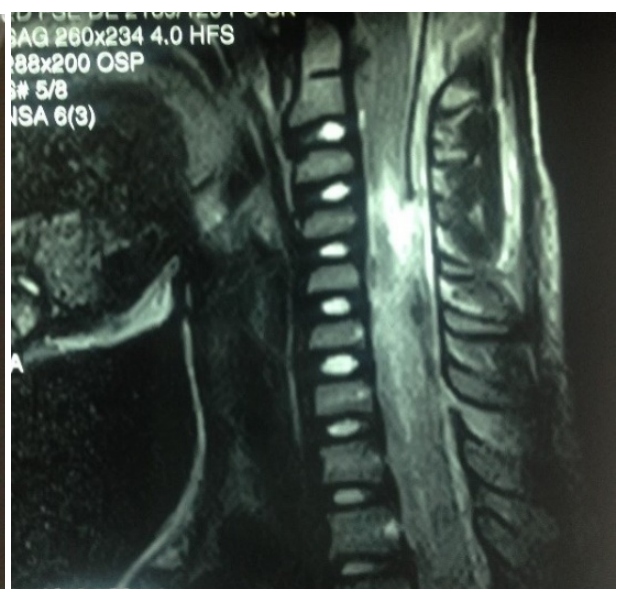

(b)

Figure 1. Neuro imaging of the case $\mathrm{N}^{\circ} 1$ with a Cervical spine CT scan normal (a) and MRI sagittal view T2 sequence showed a spinal cord contusion extended from C3 to C6 (b).

allowing a high mobility of the cervical segment, makes it more likely for post-traumatic cervical spinal cord lesions to happen in children rather than in adults. A possible explanation for SCIWORA is related to the difference in elasticity between the spinal column and the spinal cord. The less elastic spinal cord 


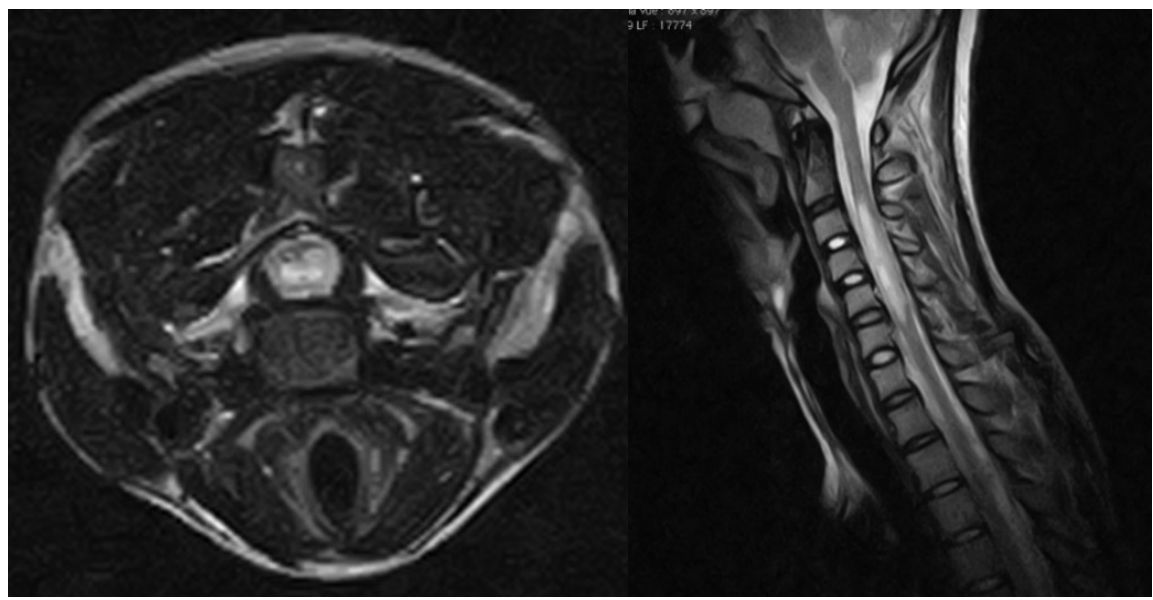

(a)

(b)

Figure 2. Neuro imaging of the case $\mathrm{N}^{\circ} 2$ with MRI axial view T2 sequence showed a spinal cord with abnormal signal (a) and MRI sagittal view T2 sequence showed a spinal cord contusion extending from $\mathrm{C} 2$ to $\mathrm{C} 6(\mathrm{~b})$.

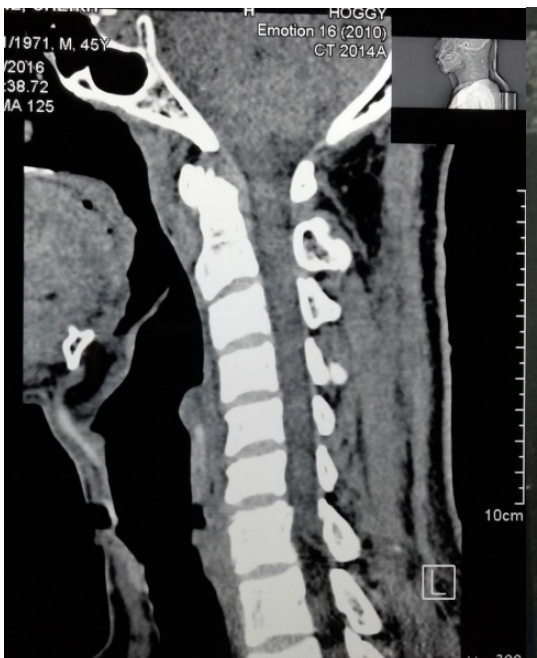

(a)

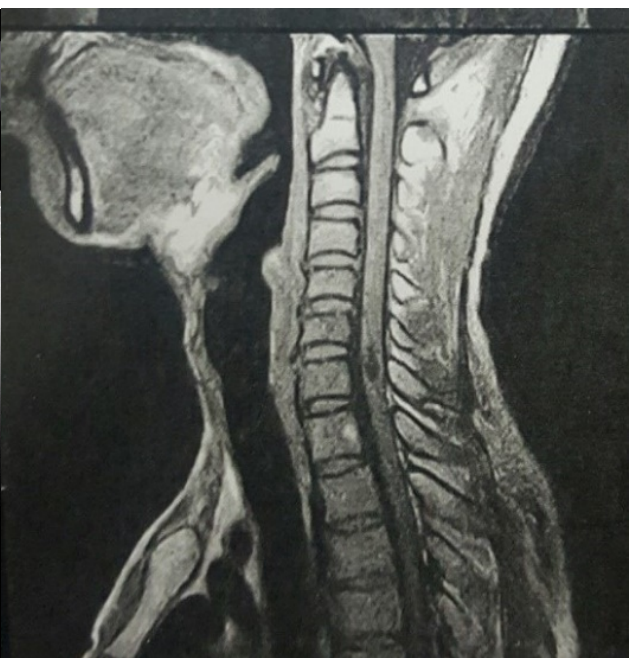

(b)

Figure 3. Neuro imaging of the case $\mathrm{N}^{\circ} 3$ with Cervical spine CT scan normal (a) and MRI sagittal view $\mathrm{T} 1$ sequence showed a syringomyelia state (b).

is more prone to injury when deformed [2] [3]. But the particularity of our series is that our patients are older with the median age around 31.7 years.

Clues to identify patient's injuries can be provided by analysis mechanism of trauma. Extension is the primary cause of SCIWORA. It is most often caused by a direct impact sustained in a motor vehicle accident or by fall from a height.

The mechanism of injury to the cervical spine is not, in fact, simply cervical hyperextension or hyperflexion as was once thought. The early, and still prevalent, understanding of whiplash injuries was that the neck was "whipped" into hyperextension and then flexion [4].

Whiplash can be considered as an acceleration-deceleration mechanism with energy transfer to the cervical spine. The events that lead to this energy transfer 


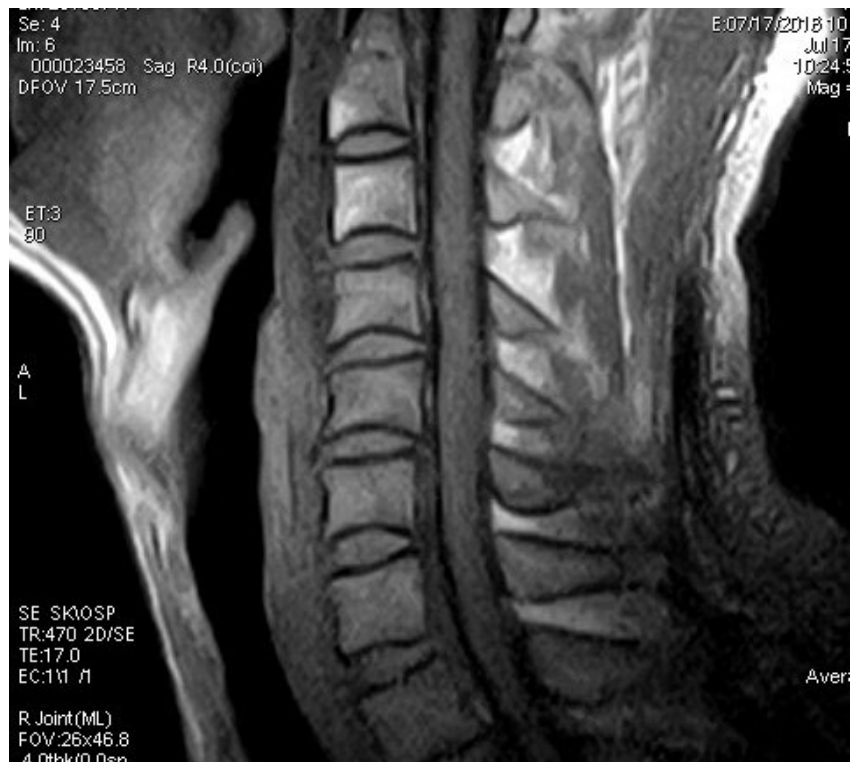

(a)

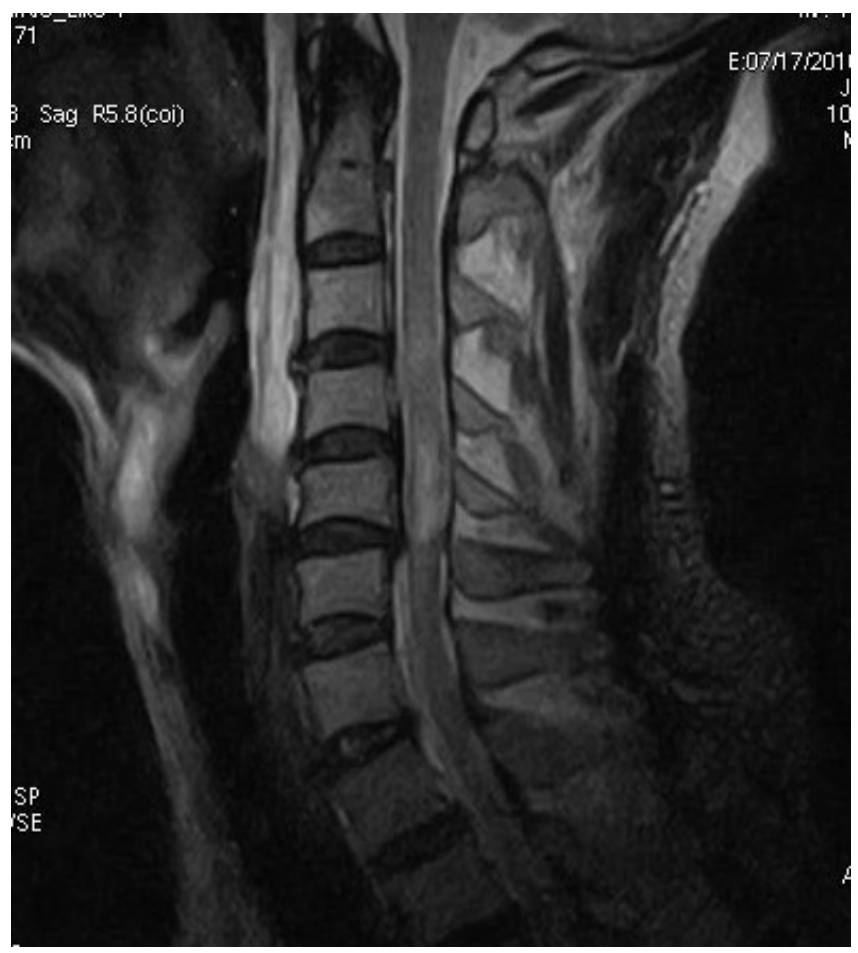

(a)

Figure 4. Neuro imaging of the case $\mathrm{N}^{\circ} 4$ with MRI sagittal view T1 sequence normal (a) and MRI sagittal view T2 sequence showed a spinal cord contusion extending from C5 to C6 (b).

include, but are not limited to, diving injuries, collisions in sporting events, side collisions and rear-end motor vehicle accidents [5]. We suspect this mechanism in some of two of our patients victims of road traffic accident.

The other suggested cause of SCIWORA is ischemia that results from direct stretch vessel injury leading to hypo perfusion of the spinal cord parenchyma 
[3]. That's probably what happened to the young woman who had a sport's accident in our series although CT angiography of supra aortic vessels rulled out arterial dissection.

SCIWORA is less common in the thoracic than in the cervical region, because the thorax and abdomen protect the thoracic vertebrae from forced excessive flexion or extension [5] [6].

The MR imaging in the evaluation of SCIWORA is the gold standard, it serves to exclude lesions that may require emergency decompressive surgery, such as extra axial hematomas and disc herniation, and it serves as a prognosis factor for neurological recovery [7] [8]. Neurological status on admission determines the long-term outcome.

The place of corticosteroid in treatment of spinal cord injuries remains questionable, but the physiotherapy is unavoidable for some recovery [2].

An initially severe neural injury is associated with a poor prognosis, where as an initially mild to moderate injury is often followed by a good recovery. However, recovery is possible for less severe cases.

\section{Conclusion}

The mismatch between the elasticity of the vertebral column and the spinal cord creates an opportunity for direct injury. Any post-traumatic myelopathy without bone lesion should require an MRI to be performed as soon as possible to yield better diagnostic information.

\section{References}

[1] Pang, D. and Wilberger Jr., J.E. (1982) Spinal Cord Injury without Radiographic Abnormalities in Children. Journal of Neurosurgery, 57, 114-129. https://doi.org/10.3171/jns.1982.57.1.0114

[2] Yamaguchi, S., Hida, K., Akino, M., Yano, S., Saito, H. and Iwasaki, Y. (2002) A Case of Pediatric Thoracic SCIWORA Following Minor Trauma. Child s Nervous System, 18, 241-243. https://doi.org/10.1007/s00381-002-0560-9

[3] Akbarnia, B.A. (1999) Pediatric Spine Fractures. The Orthopedic Clinics of North America, 30, 521-536. https://doi.org/10.1016/S0030-5898(05)70103-6

[4] Kim, C., Vassilyadi, M., Forbes, J.K., Moroz, N.W.P., Camacho, A. and Moroz, P.J. (2016) Traumatic Spinal Injuries in Children at a Single Level 1 Pediatric Trauma Centre: Report of a 23-Year Experience. Canadian Journal of Surgery, 59, 205-212. https://doi.org/10.1503/cjs.014515

[5] Trigylidas, T., Yuh, S.J., Vassilyadi, M., Matzinger, M.A. and Mikrogianakis, A. (2010) Spinal Cord Injuries without Radiographic Abnormality at Two Pediatric Trauma Centers in Ontario. Pediatric Neurosurgery, 46, 283-289. https://doi.org/10.1159/000320134

[6] Trumble, J. and Myslinski, J. (2000) Lower Thoracic SCIWORA in a 3-Year-Old Child: Case Report. Pediatric Emergency Care, 16, 91-93. https://doi.org/10.1097/00006565-200004000-00006

[7] Pang, D. (2004) Spinal Cord Injury without Radiographic Abnormality in Children, 2 Decades Later. Neurosurgery, 55, 1325-1342. 
https://doi.org/10.1227/01.NEU.0000143030.85589.E6

[8] Szwedowski, D. and Walecki, J. (2014) Spinal Cord Injury without Radiographic Abnormality (SCIWORA)—Clinical and Radiological Aspects. Polish Journal of Radiology, 79, 461-464. https://doi.org/10.12659/PJR.890944 